\title{
Efeito da sedação com xilazina e butorfanol na claudicação induzida nos membros pélvicos em equinos
}

Antônio Alcemar Beck Júnior, Stefano Leite Dau, Flávio De La Côrte, Karin Érica Brass, Bibiana Braga Lubini

Universidade Federal de Santa Maria (UFSM), Santa Maria, RS, Brasil

*Autor correspondente

e-mail: antonioabj.vet@gmail.com

\section{Resumo}

A contenção química é uma prática comum na medicina de equinos, pois possibilita a realização de diferentes procedimentos com o animal em estação, diminuindo assim seus riscos ocupacionais inerentes. Um dos protocolos mais utilizados para a realização de bloqueios anestésicos dos membros pélvicos (MPs) é a combinação de fármacos agonistas alfa-2 adrenérgicos com opióides. 0 objetivo do presente estudo foi investigar a possível interferência da sedação com cloridrato de xilazina $10 \%$ (0,3 mg/kg) (G1), isoladamente ou associado ao tartarato de butorfanol (0,01 mg/kg) (G2), na claudicação induzida no membro pélvico de cavalos sadios por meio de braçadeiras de aço inoxidável. Seis equinos (quatro fêmeas e dois machos) com idade média de 14,5 $\pm 3,83$ anos e peso corporal de $496 \pm 42,42 \mathrm{~kg}$, das raças Brasileiro de Hipismo ( $\mathrm{n}=$ 4) e SRD $(n=2)$ e de diferentes disciplinas esportivas foram utilizados. Os animais foram equipados com sensores inercias sem fio (Lameness Locator ${ }^{\circledR}$ ) para avaliação objetiva antes e após a indução da claudicação, assim como para analisar sua resposta aos tratamentos. As braçadeiras foram aplicadas e apertadas de maneira a gerar uma claudicação consistente ao trote em linha reta no exame visual (grau III na escala da AAEP) e valores médios de altura máxima (DIFFMAX) de 9,87 $\pm 5,4$ mm (G1) e 8,82 $\pm 1,74$ mm (G2) e altura mínima (DIFFMIN) da pelve de 8,55 \pm 3,45 mm (G1) e 7,36 \pm 2,07 (G2). Os animais foram aleatoriamente submetidos a ambos os tratamentos, em um modelo crossover, onde cada o cavalo era controle de si mesmo, respeitando-se um intervalo mínimo de 48 horas entre cada tratamento. A avaliação objetiva foi realizada com os animais conduzidos ao trote, em linha reta e em piso de areia, de forma que fossem obtidos no mínimo 25 passos. Os cavalos foram avaliados em quatro momentos: intensidade da claudicação présedação (M0), 20 (M2), 30 (M3) e 40 minutos (M4) após o tratamento. A resposta à sedação foi avaliada através do percentual de mudança $(\Delta \%)$ na intensidade da claudicação induzida. Pelo teste Two-way ANOVA seguido do teste de Bonferoni para comparação das médias não se observou diferença do $\Delta \%$ entre os 
tratamentos nos momentos avaliados ( $\mathrm{P}>0,05)$. Uma mudança do DIFFMAX de 15,43\% $( \pm 11,22), 18,14 \%$ $( \pm 20,85)$ e $33,98 \%( \pm 23,68)$ foi constatada nos M2, M3 e M4 no G1, e valores de $26,42 \%( \pm 31), 21,62 \%( \pm$ $26,38)$ e $41,66 \%( \pm 45,11)$ foram verificados para o G2 nos mesmos momentos. O DIFFMIN apresentou uma variação de 5,37\% ( \pm 8,97) (M2), 4,60\% ( \pm 10,07) (M3) e 4,31\% ( $\pm 7,05)(M 4)$ no G1, e valores de 8,68\% ( \pm $9,07), 14,14 \%( \pm 12,77)$ e $9,32 \%( \pm 12,79)$ para os mesmos tempos no G2. Os resultados deste estudo não corroboram a hipótese de interferência da sedação na intensidade da claudicação induzida no casco por até 40 minutos, nem apresentaram diferença entre si. Assim, a utilização de cloridrato de xilazina e tartarato de butorfanol nas doses testadas possivelmente não influenciarão na avaliação das respostas dos bloqueios perineurais e articulares dos MPs.

Palavras-chave: Agonista Alfa-2 adrenérgico. Claudicação induzida. Lameness Locator. 